\title{
DISPLACEMENT OF SHAFT DURING HYDROPOWER GENERATOR AIR GAP MEASUREMENTS
}

\author{
Marina Cerpinska, Martins Irbe, Rihards Elmanis-Helmanis \\ Riga Technical University, Latvia \\ marina.cerpinska@rtu.lv, martins.irbe@rtu.lv, rihards.elmanis-helmanis@ast.lv
}

\begin{abstract}
The objective of the study is to discuss the specific requirement of the hydropower generator health condition monitoring standard, which suggests taking into account displacement of the hydropower generator shaft when measuring the air gap. This paper quotes some research, where EMF current is used to evaluate the air gap variation considering the shaft displacement. To verify the proposed methodology, three steps were completed in this paper. Firstly, the correlation between EMF and the air gap was studied in different modes and the percentage of the change of the EMF determined by the change in the air gap was calculated. Secondly, the force vector resulting from uneven air gap is obtained using imaginary vector summation. Finally, the real values of the shaft displacement are presented and discussed. The results show that correlation between EMF and the air gap is strong, but there are also other factors that affect the EMF current, not only the air gap size. The force vector could change depending on the generation mode, but not for all units. Finally, the research shows that for the generator in healthy condition (using ISO standards as a reference for acceptable shaft displacement) the shaft displacement is only a small part of the air gap variation, approximately $2 \%$. However, the discussion part shows that it matters a lot, which evaluation standard is used, since $2 \%$ of variation is a great value, when only $3 \%$ is acceptable. To address this problem an alternative standard for dynamic air gap measurement and evaluation is quoted.
\end{abstract}

Key words: hydropower, air gap, variation, shaft displacement.

\section{Introduction}

In the last decade air gap measurements proved to be an effective health condition monitoring tool of hydropower generators, however, methods used to accomplish the measurement differ. The industry standard [1] suggests taking into account displacement of the hydropower generator shaft when measuring the air gap, but the exact method how to do it is not yet published. The example of using shaft displacement results was discussed in the paper of G.V. Glazirgin and G.E.Toropov [2]. The authors admit that the generally available method to assess the magnetic symmetry of the hydrogenerator air gap is to measure the electromotive force (EMF) generated by every pole of the generator rotor. In the paper [2] EMF sensors were used for air gap measurements and the air gap was measured mechanically between one rotor pole and the stator, and the rest of the poles calculated, based on this value. Thanks to availability of the capacitive air-gap sensors this research aims to extend the proposed methodology of [2]. Therefore, the first objective of this paper is to compare the EMF measurement results and capacitive sensor results obtained on the same generator to tell if the obvious correlation exists between magnetic symmetry and mechanical symmetry of the rotor.

As described in the papers of Ukrainian researchers [3][4], the capacitive method is the most widely used today for the air gap monitoring and is described with the following logic:

$$
C=f(d) \text {, }
$$

where $C$ - capacitance of the sensor, F;

$d$-distance between the bypass pole rotor and stator core surface, $\mathrm{mm}$.

According to the Ukrainian researchers, technological errors in air gap measurements could occur because of inclination of the sensor electrodes plane relatively to the pole surface of the rotor and curvature of the surface of the stator core[3]-[4]. These technical errors are considered, when the sensors are used to measure the air gap on bulb hydrogenerators. Since the stator slots are wider for large vertical hydrogenerators, the practical measurements on the latter provided different sources of concern.

\section{Materials and methods}

Tests were performed on salient-poles synchronous hydropower generators using Meggitt LS120 capacitive air-gap sensors. Three capacitive sensors were placed on the top of the stator, as previously described in paper [5]. 
The EMF current sensor, called also a "loop", is located at the top of the rotor, and is small. It registers the EMF current produced by the piece of the pole passing by. Registered voltage is normally not greater than $6 \mathrm{~V}$. Therefore, the absolute value of the EMF current in different modes is not analysed, and the data are used for comparison with the air gap data instead.

Mechanical gauges and micrometre were used to obtain the sensor scale.

\subsection{Resulting vector calculation}

Considering that every pole generates the mechanical force, which vector starts at the centre of the rotor, the asymmetry could be visualised using vector summation rules [6], Chapter 14, as shown in equation (2).

Resulting vector size is calculated according to equation (2):

$$
R=\sqrt{X^{2}+Y^{2}},
$$

where $R$-resulting vector;

$X, Y-$ sum of vector projections calculated according to equation (3):

$$
\begin{aligned}
& X=\sum X_{i} \\
& Y=\sum Y_{i},
\end{aligned}
$$

where $X_{i}, Y_{i}$ - vector projections to $x$ and $y$ axis obtained from equation (4):

$$
\begin{aligned}
& X_{i}=F_{i} \cos \left(F_{n}, x\right) \\
& Y_{i}=F_{i} \cos \left(F_{n}, y\right)
\end{aligned} .
$$

The resulting vector is shown in Fig. 2 in the Results section.

The air gap variation is calculated according to [7].

\subsection{Calibration}

During this study individual calibration was required for every air-gap sensor to set correctly its scale. What the user learns first about the capacitive sensor is that the output of it is usually given in Volts. To re-calculate the distance in millimetres, one should use the manufacturer sensor scale. During the measurements on site it was noted that the scale could differ from the sample provided by the manufacturer. The main reason for discrepancies was earthing quality. Unfortunately, adjustment of earthing was not possible. Therefore, calibration was needed to make corrections to the manufacturing scale.

During the calibration mechanical gauges and micrometre were used to obtain the scale. The physical distance between each sensor glued to the rotor pole and stator surface was "locked up", using the mechanical gauge (the stator surface is not even, it consists of stator laminations, and to get a correct reference value we had to be very careful), and then measured, using the micrometre. At least two measurement positions with different distances were required.

Since the rotor pole surface is not perfectly parallel to the stator surface, measuring mechanically one point to get the reference value in millimetres was not enough. Furthermore, a single measurement point would not provide enough data to create a linear scale. To make a scale, the difference of the distance should be quite significant. To get two different reference points from two different rotor poles with the same stator slot the rotor was moved clockwise with the hand jack.

\section{Results and discussion}

\subsection{EMF current and capacitive sensor results}

To tell, if the obvious correlation exists between magnetic symmetry and mechanical symmetry of the rotor, the EMF current and capacitive sensor results are compared for the same modes, using the 
Pearson coefficient [8]. Fig.1 illustrates the EMF measurement results in different mode, represented in Volts on the scale from $2 \mathrm{~V}$ to $5 \mathrm{~V}$ with dotted lines.

The capacitive sensor results in 90 MW 0 MVAr mode are presented on the secondary scale from $10 \mathrm{~mm}$ to $35 \mathrm{~mm}$ with the solid line. Respective results of the air gap size are given for one generation mode to make better visual comparison.

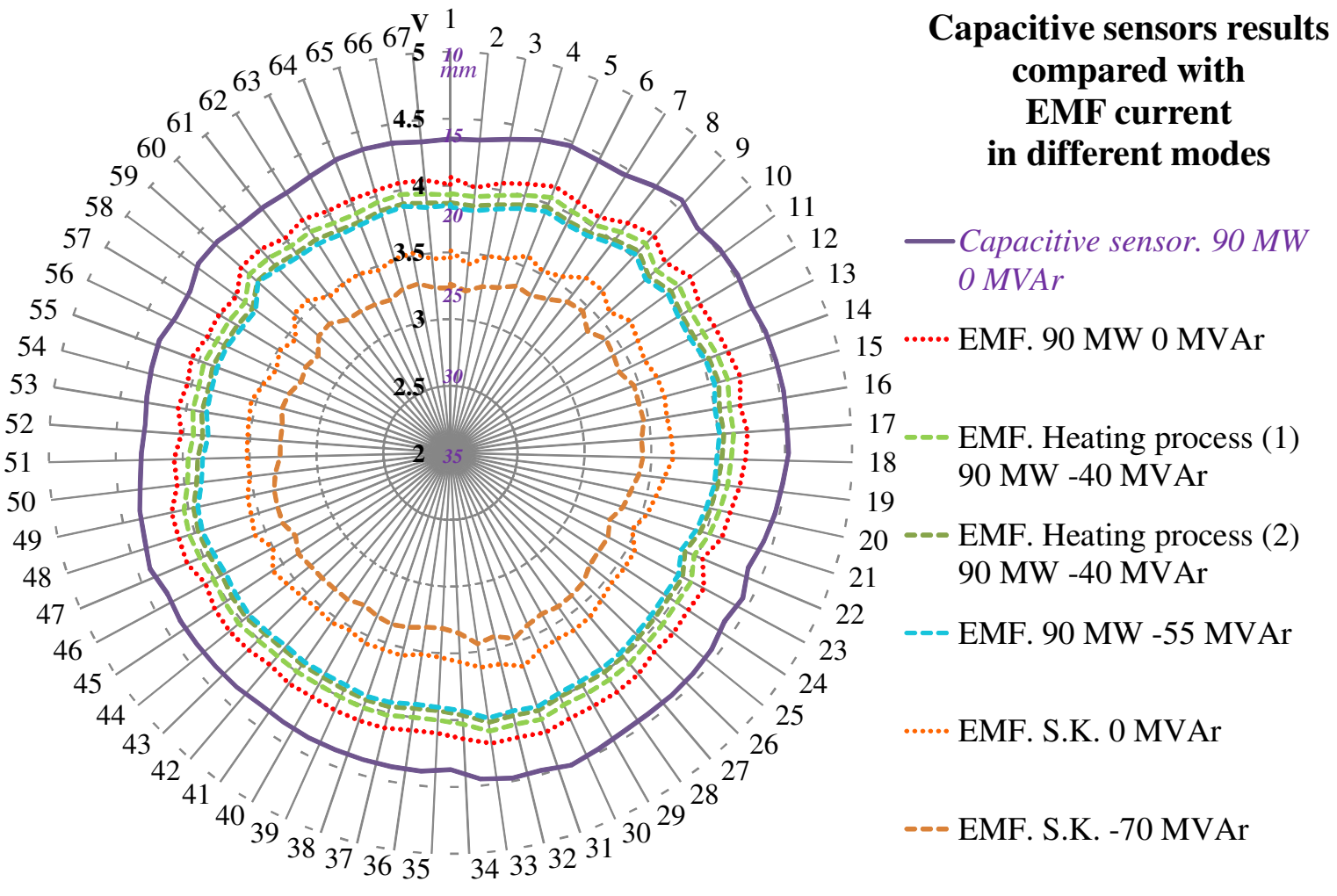

Fig. 1.EMF current in different modes

Visual assessment of the experimental data tells shat the EMF current is more even, whereas capacitive sensor results show some asymmetrical behaviour, but the expected correlation is strong. Table 1 shows that in the synchronous condenser mode the correlation is weaker than in generation modes with nominal active power, but it is still strong for two of three sensors.

Table 1

\section{Correlation of EMF current and capacitive sensor results for Unit 1}

\begin{tabular}{|c|c|c|c|c|c|c|c|c|c|}
\hline \multirow{2}{*}{$\begin{array}{l}\text { Generation mode } \\
\text { Correlation of air } \\
\text { gap asymmetry } \\
\text { from capacitive } \\
\text { sensor and EMF } \\
\text { current for: }\end{array}$} & \multicolumn{3}{|c|}{$\begin{array}{c}\text { Results in } 90 \text { MW } 0 \\
\text { MVAr mode }\end{array}$} & \multicolumn{3}{|c|}{$\begin{array}{c}\text { Results in } \\
\text { Synchronous } \\
\text { condenser mode } \\
\text { with } 0 \text { MVAr }\end{array}$} & \multicolumn{3}{|c|}{$\begin{array}{c}\text { Results in } \\
\text { Synchronous } \\
\text { condenser } \\
\text { with -70 MVAr mode }\end{array}$} \\
\hline & $\begin{array}{c}1 \text { st } \\
\text { sensor }\end{array}$ & $\begin{array}{l}\text { 2nd } \\
\text { sensor }\end{array}$ & $\begin{array}{l}\text { 3rd } \\
\text { sensor }\end{array}$ & $\begin{array}{c}1 \text { st } \\
\text { sensor }\end{array}$ & $\begin{array}{l}\text { 2nd } \\
\text { sensor }\end{array}$ & $\begin{array}{c}\text { 3rd } \\
\text { sensor }\end{array}$ & $\begin{array}{c}1 \text { st } \\
\text { sensor }\end{array}$ & $\begin{array}{l}\text { 2nd } \\
\text { sensor }\end{array}$ & $\begin{array}{c}\text { 3rd } \\
\text { sensor }\end{array}$ \\
\hline Pearson coefficient & -0.9 & -0.9 & -0.9 & -0.8 & -0.8 & -0.8 & -0.9 & -0.9 & -0.9 \\
\hline $\begin{array}{l}\text { Is there a } \\
\text { correlation? }\end{array}$ & yes & yes & yes & yes & yes & yes & yes & yes & yes \\
\hline Determination & $82 \%$ & $80 \%$ & $82 \%$ & $71 \%$ & $65 \%$ & $71 \%$ & $77 \%$ & $77 \%$ & $75 \%$ \\
\hline Correlation strength & strong & strong & strong & strong & week & strong & strong & strong & strong \\
\hline
\end{tabular}

The Person coefficient is negative since for the poles with the smaller air gap (in millimetres) the EMF current is greater (in Volts), that is also why in Figure 1 one axis has reversed order. 
Determination of $65-82 \%$ means that $65-82 \%$ of the change in the EMF current could be explained by the change of the air gap size, while the rest, $35-18 \%$ could not. Thus, even when correlation is strong, there are other factors that affect the EMF current, not only the air gap size. Other influencing factors could be, for example, winding mechanical quality, EMF sensors quality, earthing quality on site.

Correlation of EMF current and capacitive sensor results for Unit 2

Table 2

\begin{tabular}{|l|c|c|c|c|c|c|c|c|c|}
\hline Generation mode & \multicolumn{3}{|c|}{$\begin{array}{c}\text { Results in 90 MW 0 } \\
\text { MVAr mode }\end{array}$} & \multicolumn{2}{c|}{$\begin{array}{c}\text { Results in } \\
\text { Synchronous } \\
\text { condenser mode with } \\
\text { 0 MVAr }\end{array}$} & \multicolumn{2}{c|}{$\begin{array}{c}\text { Results in } \\
\text { Synchronous } \\
\text { condenser with -50 } \\
\text { MVAr mode }\end{array}$} \\
\hline $\begin{array}{l}\text { Correlation of air } \\
\text { gap asymmetry } \\
\text { from capacitive } \\
\text { sensor and EMF } \\
\text { current for: }\end{array}$ & $\begin{array}{c}\text { 1st } \\
\text { sensor }\end{array}$ & $\begin{array}{c}\text { 2nd } \\
\text { sensor }\end{array}$ & $\begin{array}{c}3 \mathrm{rd} \\
\text { sensor }\end{array}$ & $\begin{array}{c}1 \text { st } \\
\text { sensor }\end{array}$ & $\begin{array}{c}\text { 2nd } \\
\text { sensor }\end{array}$ & $\begin{array}{c}3 \mathrm{rd} \\
\text { sensor }\end{array}$ & $\begin{array}{c}1 \text { st } \\
\text { sensor }\end{array}$ & $\begin{array}{c}2 \mathrm{nd} \\
\text { sensor }\end{array}$ & $\begin{array}{c}3 \mathrm{rd} \\
\text { sensor }\end{array}$ \\
\hline Pearson coefficient & -0.5 & -0.5 & -0.5 & -0.8 & -0.8 & -0.8 & -0.9 & -0.9 & -0.9 \\
\hline $\begin{array}{l}\text { Is there a } \\
\text { correlation? }\end{array}$ & yes & yes & yes & yes & yes & yes & yes & yes & yes \\
\hline Determination & $27 \%$ & $26 \%$ & $27 \%$ & $72 \%$ & $72 \%$ & $71 \%$ & $76 \%$ & $74 \%$ & $75 \%$ \\
\hline Correlation strength & week & week & week & strong & strong & strong & strong & strong & strong \\
\hline
\end{tabular}

Table 2 shows that for Unit 2 the correlation is not so strong in all generation modes as for Unit 1. It is rather week in the generation mode with rated active power $90 \mathrm{MW}$. Determination of 26-27\% means that 73-74 \% of the change in the EMF current could not be explained by the change of the air gap size. Consequently, EMF current measurements could not always be used as proposed in paper [2] as a substitution of air gap measurements with capacitive sensors.

\subsection{Vector force results}

Shaft displacement in different modes is analysed, when the balancing of the hydropower generator is performed. Therefore, the vector force was created for the air gap measurement data as well as to test, if this analysis could be useful for the balancing.

Fig. 2 tells that for Unit 1 the vector force changes slightly depending on the generation mode. For Unit 2 the vector force did not change. In general, these data are less useful than the shaft displacement data for balancing.

\subsection{Shaft displacement results}

According to ISO 7919-5 [9] standard the acceptable shaft displacement limit for the upper thrust bearing (in the range $0.5-30 \mathrm{~Hz}$, measured as Peak-to-Peak value from RMS) is under $265 \mu \mathrm{m}$. Table 3 summarises the results for Unit one and Unit 2 in micrometres $(\mu \mathrm{m})$ and converted into millimetres $(\mathrm{mm})$, because micrometres are used for vibration and shaft displacement measurement and evaluation, while millimetres are used for air gap measurements. The nominal air gap of Unit 1 was $17 \mathrm{~mm}$, for Unit $2-18 \mathrm{~mm}$.

Table 3

\section{Generator shaft displacement results for unit under study}

\begin{tabular}{|l|c|c|c|}
\hline Measurement position & $\begin{array}{c}\text { Overall } \\
\text { value, } \boldsymbol{\mu m}\end{array}$ & $\begin{array}{c}\text { Overall value, } \\
\mathbf{~ m m}\end{array}$ & $\begin{array}{c}\text { Percentage of the } \\
\text { nominal air gap, \% }\end{array}$ \\
\hline Unit 1. Generator bearing X direction & 310 & 0.310 & 1.82 \\
\hline Unit 1. Generator bearing Y direction & 298 & 0.298 & 1.75 \\
\hline Unit 2. Generator bearing X direction & 63 & 0.063 & 0.35 \\
\hline Unit 2. Generator bearing Y direction & 68 & 0.068 & 0.38 \\
\hline
\end{tabular}




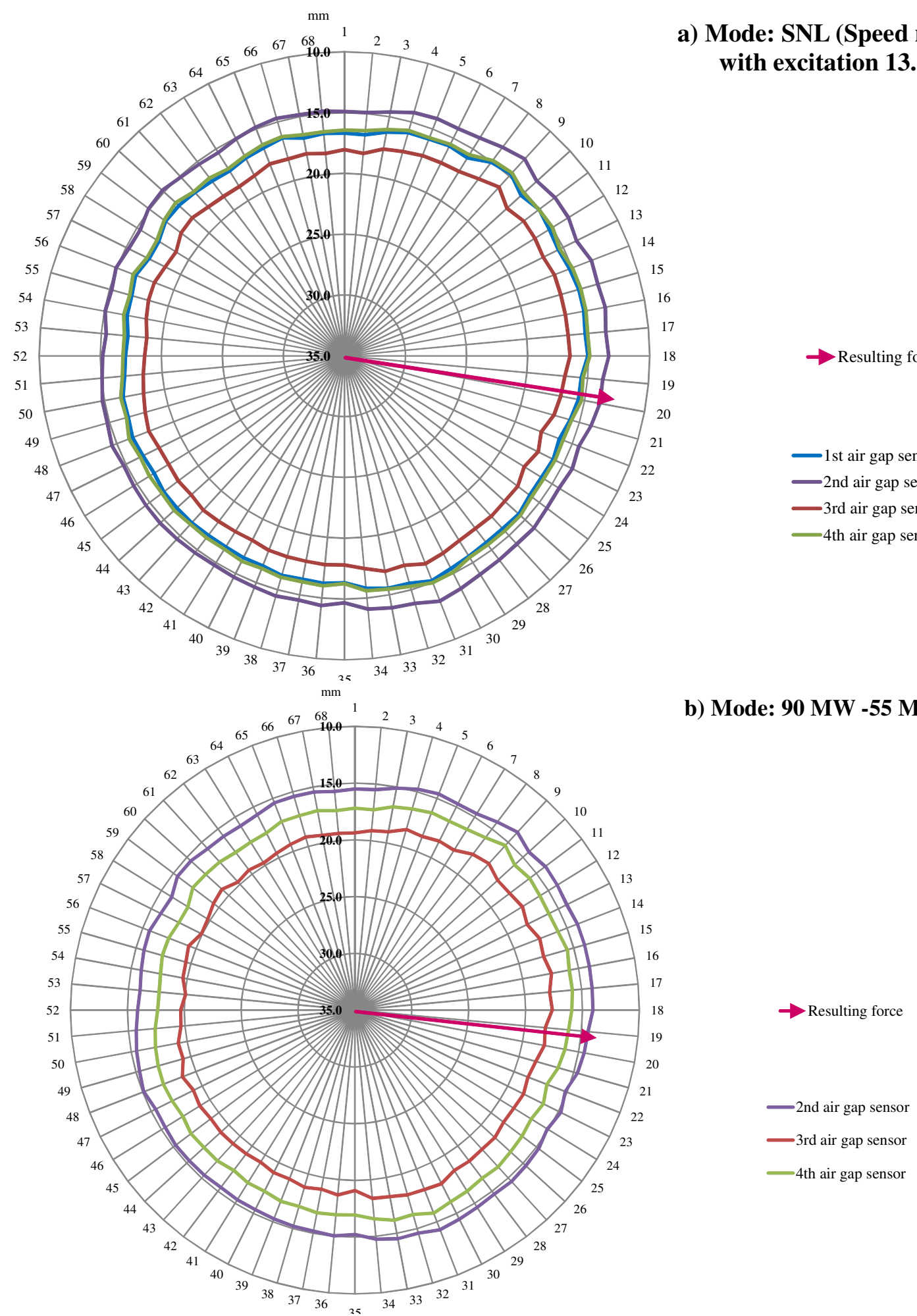

Fig. 2.Vector force of asymmetry assessed from experimental results - Unit 1: a - SNL mode; $b$ - 90 MW -55 MVAr mode

From Table 3 it could be concluded that shaft displacement for Unit 1 exceeds the suggested standard value, while for the Unit 2 shaft displacement has the value characteristic to the units in good condition. The greatest generator shaft displacement registered was $0.3 \mathrm{~mm}$. Considering that the nominal air gap is $17 \mathrm{~mm}$ large, this is less than $2 \%$. For Unit 2 the low shaft displacement was only $0.4 \%$ of the nominal air gap considering that the nominal generator air gap was $18 \mathrm{~mm}$.

At this stage it matters a lot, which evaluation standard is used. The authors of paper [2] truly noted that $2 \%$ variation is great, when only $3 \%$ is acceptable. At the same time, $2 \%$ of the variation 
is a result of unacceptably high shaft displacement, so the generator should be expected more closely. Following the alternative industry standard [10] created for dynamic air gap, the user would learn that $10 \%$ of dynamic air gap variation is satisfactory for the unit, which is in operation for more than 5 years. Therefore $2 \%$ is not a critical portion of the variation. The other sources of variation were discussed in the previous publication [5], but the unit studied was of a slightly different design. It was shown that the force of inertia and temperature effects have a critical role for the air gap variation. For Unit 1 in this study the inertia force accounted for only $0.2 \mathrm{~mm}$ of the variation, which is less than $0.7 \mathrm{~mm}$ quoted in the previous research [5]. Temperature effects accounted for $1.5 \mathrm{~mm}$, which supports the previous conclusions that the thermal expansion effects could cause up to $90 \%$ of the air gap variation. Neither change of the active or reactive power affected the air gap variation in both studies.

\section{Conclusions}

Summing up the shaft displacement effect on the air gap variation, the results on the particular units are as follows:

1. For the healthy generator the shaft displacement is relatively small comparing to the air gap. For instance, the nominal air gap of the hydropower generator could be $20 \mathrm{~mm}$, and the displacement of the shaft according to ISO 7919-5 for vertical machine sets should be $0.265 \mathrm{~mm}$ only. It is less than $2 \%$ of the nominal air gap.

2. Shaft displacement should be considered for the air gap measurements, and it should be noted that it is the only variation source, which affects the measurement in all generation modes.

3. However, the variation due to shaft displacement should never be simply extracted from the overall air gap variation before the evaluation, because, when the standard for the dynamic air gap is used, the acceptable variation is $10 \%$, not $3 \%$ as for the static air gap measurement, therefore the displacement of the shaft is an inherent part of $10 \%$ variation.

The results also showed that EMF current results could not be used instead of capacitive sensors for the air gap measurements, because the correlation was not always strong.

\section{References}

[1] STO 17330282.27.140.001-2011. Methods for Evaluating the Technical Condition of Major Hydroelectric Plant Equipment (in Russian: Стандарт ОАО РАО "Методики оценки технического состояния основного оборудования гидроэлектростанций”).

[2] Глазырин Г.В., Торопов Г.Э., Бурматов А.П.Определение динамической формы ротора гидрогенератора с учетом перемещений вала (Determination of hydrogenerator rotor dynamic shape considering displacement of the shaft). Избранные труды НГТУ - 2004: Сб. науч. трудов. - Новосибирск: изд-во НГТУ, 2004. (In Russian).

[3] Zaitsev I.O., LevytskyiA.S., KromplyasB.A.Characteristic of capacitive sensor for the air gap control system in the hydrogenerator. Proceeding of First Ukraine Conference On Electrical And Computer Engineering (UKRCON), May, 2017, pp. 390-394.

[4] Zaitsev, I. O.,Levytskyi A. S. Determination of response characteristic of capacitive coplanar air gap sensor. Proceedings of IEEE Microwaves, Radar and Remote Sensing Symposium (MRRS), August,2017, pp. 85-88.

[5] Čerpinska M., Elmanis-HelmanisR. Dynamic Air Gap Change of Low-Speed Generator Considering Thermal Expansion, Centrifugal Force and Magnetic Force Effects. Latvian Journal of Physics and Technical Sciences, Vol.5, No.5, 2017, pp. 26-37. Available at: doi:10.1515/lpts2017-0031

[6] Николаи Е.Л. Теоретическая механика в 2 частях. (Engineering mechanics in two parts) Часть 1. Москва: Госиздат технико-теоретической литературы, 1952. 304 p. (In Russian).

[7] Guide for Erection Tolerances and Shaft System Alignment. 1989. Canadian Electrical Association (CEA) (Guide technique-Division Étudeset Normalisation, VP Ingénierie HQ).

[8] Ross S.M. Introduction to probability and statistics for engineers and scientists. 3rd edition. USA: Elsevier Academic Press, 2004. 624 p.

[9] ISO 7919-5:2005 Mechanical vibration -- Evaluation of machine vibration by measurements on rotating shafts -- Part 5: Machine sets in hydraulic power generating and pumping plants.

[10] IEEE Std 492-1999 (R2011) IEEE Guide for Operation and Maintenance of Hydro-Generators. 